\title{
Application of Zero base Budget in Maintenance Operation and Maintenance Fee of County Power Supply Company
}

\author{
Lin Zhihong \\ North China Electric Power University \\ School of Economics and Management \\ Baoding, China \\ lzh13730225252@163.com
}

\author{
Wu Yueqing* \\ North China Electric Power University \\ School of Economics and Management \\ Baoding, China \\ 1534278914@qq.com
}

\begin{abstract}
At present, China's State Grid county budget amount is still based on the historical data and the annual budget line for reference to determine, but the status quo of the development of the counties brings resistance. In order to adapt to the "three sets of five" financial intensive construction requirements, we must give full play to the guiding role of budget management, which for achieving the rational allocation of limited funds for the weak link of the power grid and eliminating short board assets in regional power grid target. To determine the zero based budget theory and re measure the company expense demand by the analysis of the current municipal power supply company budget management status. In this paper, it show that the terrain and the type of lines are the two key factors by the understanding of the influence factors of the overhaul cost and daily maintenance cost, and maintenance operation and maintenance costs budget decomposition formula is obtained by the terrain correction coefficient and line type correction coefficient. Finally, we can make a more scientific and reasonable budget decomposition on the basis of the zero based budget theory by changing the budget decomposition method of power supply company.
\end{abstract}

Keywords-Power grid; zero base budget; incremental budget; budget decomposition

\section{INTRODUCTION}

In 2011 the county power supply company is to become the province's subsidiary company, counties as a profit center, maintenance operation and maintenance costs of the budget is to increase budget theory, which is based on the actual amount of the previous year, the unit profit budget period into account, combined with the budget period to be adjusted due to budget determined. In the electricity sales, the sale of electricity, the power purchase cost is different, each unit gross profit difference. Under its influence, the budget of the company between counties is large, resulting in maintenance of power grid assets guarantee excellent operation and maintenance costs budget imbalance. The unit profit margins, because the cost of power grid assets good enough, The units with small profit margins are obviously lower than those with large profit margins due to insufficient costs, grid assets specifications, standards and operational reliability, thus becoming the "short board" at the county level power supply companies in the province.

At the beginning of 2016, the company completed the "sub county reform" transformation work, to explore the zero based budgeting theory as the guidance and maintenance of company operation and maintenance costs budget decomposition, to make the county company maintenance operation and maintenance costs budget is no longer affected by the previous level, but rather focus on the unified maintenance area of power grid assets to zero as the starting point, excellent. To the actual status of assets budget period counties company based, in accordance with the requirements of maintenance operation and maintenance costs budget, eliminate before incremental budget is too dependent on the historical data and the profit space of this defect, the rational allocation of resources to achieve the maximum, the assets of the company in the uneven situation improved.

\section{APPLICABILITY OF ZERO BASED BUDGETING}

\section{A. The basic theory of Zero based budgeting}

Essentially, the budget is the power and responsibility of the internal arrangement of the various levels of management budget, which is adapted to the corporate strategy, organization structure and corporate governance structure. To achieve the company's internal control and management mechanism through the arrangement of right and responsibilities and benefits. The rules of the game between the range. Company owners and operators is a principal agent relationship. Not the traditional incremental budget compilation method to solve such a contradiction, the operators for the pursuit of short-term operating performance and damage the owner of long-term benefits [1]

The zero based budget budgeting method, which can solve the above contradiction. First of all, in the zero base budgeting, each department must proceed from the actual situation analysis, which can mobilize the departments management staff's enthusiasm and creativity, and to strengthen the planning, budget control and decision making. Secondly, each department must be very careful in using the funds reasonably, 
controlling the actual business activities in accordance with the budget target and improving the effect of the use of funds in the zero based budget execution. Finally, zero base budget is the company departments performance rewards and punishment standards, which is an important tool for the evaluation of work departments at all levels of performance and operating results [2].

The main characteristics of zero based budgeting are as follows [3]:

1) Start the budget plan from scratch : According to the annual allocation of tasks considering the budget, it can achieve the organic unity of the budget and task combination.

2) The procedure of determining the budget plan is complicated and complicated: The program through the decision making package, sorting, audit and other multichannel program, whose compiling process takes a long time, heavy workload.

3) Evaluation of rationality of the budget : According to the company's annual development goals and business decisions and detailed assessment of each business to assess a more reasonable budget plan.

4) To strengthen the budget scrutiny : In accordance with the task of the new year, the personnel and the cost standard to conduct a comprehensive review about the budget plan without the budget budget arrangements last year.

\section{B. Comparison of Zero base budget and Traditional budget}

\section{1) The foundation of the budget}

a) Zero base budget

Starting with zero, which determines the specific amount in accordance with the budget available for allocation of resources.

\section{b) The traditional budget}

The final accounts results of the above years shall be the starting point, and shall be adjusted after considering the cost control experience of the previous year and considering the expenses required for the new business in this period.

\section{2) Budget control objective}

\section{a) Zero base budget}

The budget control objective is subordinated to the overall objective of the enterprise

\section{b) The traditional budget}

From the monetary point of view, the amount of money or more or less to determine the effect of budget execution.

\section{3) Content of budget analysis}

\section{a) Zero base budget}

The first is to predict the business volume, to determine their importance by the cost-benefit analysis, so as to determine the allocation of resources.

b) The traditional budget
The key is to do a cost-benefit analysis of new business, and for the past similar activities is to use the original budget or for the same proportion of adjustment [4].

\section{4) Budget priorities}

a) Zero base budget

The analysis focuses on the business of the work itself, considering the problem from business activities, and determine the level of income and expenses after the analysis of every business activities one by one.

\section{b) The traditional budget}

The emphasis is only on the increase or decrease of the budget amount, rather than on the analysis of the work itself [5].

\section{5) Scope of cost and benefit analysis}

a) Zero base budget

A cost effectiveness analysis of all business activities in the past and future is required.

\section{b) The traditional budget}

It only needs the Cost benefit analysis of future business activities.

\section{6) Deal with new and old business}

a) Zero base budget

Regardless of the new and old business, we should consider its impact on the budget and cost and benefit analysis should be used to determine its importance, and determine the level and efficiency of expenditure according to the importance.

\section{b) The traditional budget}

Just consider the impact of new business changes on the budget, the new business does not increase, the budget does not change [6].

\section{MAINTENANCE OPERATION AND MAINTENANCE COSTS BUDGET DECOMPOSITION SCHEME DESIGN}

\section{A. The scope of maintenance operation and maintenance costs}

The cost estimating of Maintenance operation and maintenance costs including overhaul fee and daily maintenance fee needs conducted respectively. The overhaul cost factors include line length, wire type (cross-sectional area), terrain, load rate and service age of assets, and the daily maintenance cost factors include line length, tree barrier, equipment allocation and power grid construction in construction project in total, overhaul, and operation status of transformer and JP cabinet [7].

Combining the effect factors of the overhaul cost, the overhaul cost of different terrain, different types of line overhaul costs were estimated in the single factor analysis method. The items of the daily maintenance fee are miscellaneous and scattered, and the amount of them is closely related to the overhaul cost. The amount of it has certain regularity each year, and the proportion of the total 
maintenance costs are relatively fixed. In addition, it is not the main factors to affect the maintenance operation and maintenance costs budget breakdown, only the maintenance costs accounted for the overall proportion estimates.

\section{B. The calculation of the maintenance operation and maintenance costs}

Quantitative control index for each company maintenance operation and maintenance costs budget, and auxiliary index correction for terrain correction coefficient and line model coefficients in the budgeting process decomposition scheme.Non quantitative indicators are electricity sales trends and capital equipment service age. Using the zero based budgeting method in company operation and maintenance costs and maintenance budget decomposition, and to examine the completion of the audit budget in the final. For further control the implementation of the budget, the actual expenditure amount and the amount of the budget deviation decomposition should be in a reasonable range.

\section{1) Parameter determination}

a) Determine the topographical features of each county

Some county in the plain, some county in the mountains, and some county somewhere between in the two. According to this situation, the county is divided into plain, mountainous and semi mountainous three types. In plain area as a base to determine the terrain correction parameters.

\section{b) Clean up the assets to be repaired}

According to the information system of PMS company about the wire, through the wire type which does not reach the state of the main lines and branch lines, and the wire served more than 10 years of age were screened out. Select the line to be repaired and then calculate the repair line length.

\section{2) Define budget decomposition plan}

The liquidation results of the assets in different counties are multiplied by the corresponding correction factors, so that the assets between the counties are comparable. At the same time, considering the development trend of the future electricity sales in different county, maintenance operation and maintenance costs of increased or reduced. Then the maintenance of all operation and maintenance costs are budget decomposition.

The budget decomposition formula is:

$$
\begin{aligned}
S & =S_{1}+S_{2} \\
& =\sum_{i=1}^{n} C_{i}+\sum_{i=1}^{n} D_{i}
\end{aligned}
$$

S - The total amount of maintenance operation and maintenance costs budget

$$
\begin{aligned}
& S_{1} \text { - County overhaul budget } \\
& S_{2} \text { - in the daily maintenance budget } \\
& C_{i} \text { - in overhaul budget } \\
& D_{i} \text { - a daily maintenance budget } \\
& n \text { - The number of counties }
\end{aligned}
$$

$$
G=\left(M_{1} \times A_{1}+M_{2} \times A_{2}+M_{3} \times A_{3}\right) \times B
$$

$\mathrm{G}$ - a wire to be repaired after correction length

$\mathrm{M}_{1}$ - a plain wire length

$\mathrm{M}_{2}$-- lead in mid length

M3 - a mountain wire length

$\mathrm{A}_{\mathrm{i}}$ terrain correction coefficient,

B - said the model correction coefficient of line.

In the overhaul budget calculation formula is as follows:

$$
C i=\frac{G_{i}}{\sum_{i=1}^{n} G_{i}} \times S_{1}
$$

$$
\begin{aligned}
& \mathrm{C}_{\mathrm{i}} \text { - in overhaul budget } \\
& \mathrm{G}_{\mathrm{i}} \text { - a wire to be repaired after correction length }
\end{aligned}
$$

\section{EVALUATION AND IMPROVEMENT}

\section{A. Assessment method}

In the budget management system of the national grid, the local power supply company as the basic unit of budget management not only needs to measure, report preparation, the budget of the units, but also needs to determine the operating principle according to the budget index of the national final approval issued by the Power Grid Corp, business management. Practical verification is the professional management evaluation method, to which assesses whether the budget decomposition plan is scientific and reasonable through the audit way.

The detailed steps are as follows. According to the data of field investigation of typical county companies, the budget standards of maintenance and operation and maintenance, and the actual situation of the assets to be repaired are calculated, so as to make a budget decomposition for the counties and companies. After a year, the maintenance fee for each specific application feedback to the company, then the company audit city and county power supply company maintenance operation and maintenance costs and the amount of the actual activities, and compared with the original budget, calculate the actual amount and budget deviation. If the deviation is too large, the budget standards need to be improved and further calculations and tests are geedpd.If the deviation is ngt obvious, it shows that the budget standard of measurement is more practical, and can be continued for later observation.

\section{B. Assessment method}

\section{1) Planning aspect}

As the budget management chain is long, and the specific circumstances of the county power supply companies are different. It is impossible to formulate a set of budget management plan for all county power supply companies in the maintenance and operation and maintenance costs. 
Therefore, according to the results of decomposition scheme and only several County, field research and the development of the budget standard may not be well adapted to the county, part of the county company will have a large deviation, and the budget implementation lacks rigid.

\section{2) Implementation aspect}

The level of financial budget management depends largely on the overall quality of financial personnel, which not only requires financial budget management knowledge, enterprises involved in all aspects of business activities should be understood and mastered. At present, the overall quality of financial personnel has not yet reached such a high standard. The actual number of actual power supply provided by the county power supply company will affect the accuracy of the final results because of different accounting methods.

\section{3) Evaluation aspect}

In the evaluation process, the company does not necessarily result in feedback for making maintenance operation and maintenance costs budget. The determination of operation and maintenance costs budget standards for counties company maintenance, and it is just for the provincial company issued a determination, the standard model line in the file so it has certain limitations. If standards change, then the budgeted cost of the line overhaul will no longer be applicable, but the budget standards for the new model will need to be measured.

\section{CONCLUSION}

The electric power industry is the basic industry of the national economy, which has a huge impact on the national economy and the people life, producing. At present, ensuring safety is the core objective of energy development in the world. The main objective of energy security is to achieve a stable, reliable, economic and clean energy supply, and the key is to solve the four major issues of resources, allocation, efficiency, environmental protection issues.
This paper discusses the zero based budgeting theory as the guide for county power supply company maintenance operation and maintenance costs budget decomposition, which is not to make the county company maintenance operation and maintenance costs budget affected by the previous level, but focus on the maintenance of a unified power grid assets with zero starting point and based on the actual status of assets budget period counties company. According to the demand of maintenance operation and maintenance costs budget, it can eliminate that the incremental budget is too dependent on historical data and the defects of the profit space, and to achieve the rational allocation of resources maximum and the assets of the company in the uneven situation will be improved at the same time. Proposing the new ideas of budget management which can adapt to the current environment is greatly enrich the existing theory. At the same time, county power supply company can operate the grid maintenance operation and maintenance costs efficiently, which will has a very important significance on the rural power grid safety and the economic and reliable operation, the healthy development of the rural economy society and the quality of life.

\section{REFERENCES}

[1] Li Hong. Study on the implementation of zero budget reform in China [J]. business economics, 2014, (05): 164-167.

[2] Wang Yu in Shihua. Rate, selection and application of [J]. incrementa budget and zero based budgeting in strategic control in the process of Inner Mongolia coal economy, 2013, (06): 11.

[3] Yang Jianqiu. Research on budget management of power supply enterprise [D]. A, South China University of Technology, 2014.

[4] Qin Lu. [J]. budgeting methods of comprehensive budget managemen in the new accounting, 2015, (04): 36+51.

[5] Liu Wenjun. Research on comprehensive budget management system of county power supply enterprises [D]. North China Electric Power University, 2015.

[6] Wang Mingyue. Based on the national grid budget management system RZ power supply company budget management optimization research [D]. Shandong University, 2014.

[7] Wang Yu, Yu Yu, Hua Hua. The application of incremental budget and zero base budget in the process of strategic control [J]. Inner Mongolia coal economy, 2013, (06): 11.(In Chinese) 